\title{
Perception of Heat in Cheese Sauces as Affected by Capsaicin Concentration, Fat Level, Fat Mimetic and Time
}

\author{
L. A. Carden, M.P. Penfield, and A. M. Saxton
}

\begin{abstract}
Perceived heat intensity in cheese sauces with five capsaicin levels, three fat levels and four fat mimetics was studied with time intensity techniques. Heat intensity was not related to fat mimetic. No differences occurred among fat levels at 0.0 and $0.4 \mathrm{ppm}$ capsaicin. At $0.8 \mathrm{ppm}$ capsaicin, maximum and total heat intensities of reduced-and low-fat sauces were equal; both were lower in full-fat sauces $(p<0.001)$. Low-fat sauces exhibited greater maximum heat and total intensity than full-fat at $1.2 \mathrm{ppm}$ capsaicin. At $1.6 \mathrm{ppm}$ capsaicin, lowfat sauces had greater total intensity than either reduced- or full-fat $(p<0.05)$ sauces. At low-fat levels, lower capsaicin concentrations provided heat equal to higher concentrations in full-fat cheese sauces.
\end{abstract}

Key Words: capsaicin, heat, time intensity, fat mimetic, fat level

\section{INTRODUCTION}

THE SURGEON GENERAL'S REPORT (USDHHS, 1988) ON THE health of Americans created consumer demand for decreased-fat products. This demand led to the introduction of several fat replacement systems, including hydrocolloids, starch derivatives and microparticulated proteins (Glicksman, 1991). Use of fat replacers introduced new concerns to food manufacturers. Lipid-based flavor volatiles may be affected by a decrease in fat through introduction of carbohydrate and/or protein replacements. Without fat, the lipophilic flavors may not be bound tightly and may be released more rapidly and in greater concentration into the oral cavity headspace (Plug and Haring, 1993). Shamil et al. (1992) measured flavor release and perception in reduced and full-fat versions of cheddar and Edam cheeses and in salad dressings formulated with full fat and with two fat replacers. They concluded that the fat/ water ratio in foods affects bitter tastes which are hydrophobic and as such may be released more easily by the hydrophilic environment created with fat replacers. Rosin and Tuorila (1992) reported no differences in intensity of garlic flavor dispersed in various foods. However, perceived intensity of black pepper with or without garlic was stronger in fat-free mashed potatoes than in those containing fat.

Americans have developed an interest in products with heat which is provided by capsicum peppers. Heat of chilies derives from a group of capsaicinoids; capsaicin (N-vanillyl-8-methyl-6-nonenamide) is the most predominant (Bosland, 1992). The presence of capsaicin is recognized as a sensation of "burning;" when ingested, the alkaloid irritates or stimulates trigeminal nerves in the oral cavity (Prescott et al., 1984). A linear relationship between concentration of capsaicinoids and intensity of heat was established by Krajewska and Powers (1988).

Author Carden is with the Dept. of Human Environmental Sciences, School of Agriculture \& Human Environments, The Univ. of Tennessee, Martin, TN. Author Penfield is with the Dept. of Food Science \& Technology, The Univ. of Tennessee and Tennessee Agricultural Experiment Station, P.O. Box 1071, Knoxville, TN 37920-1071. Author Saxton is with the Dept. of Animal Science and Tennessee Agricultural Experiment Station, The Univ. of Tennessee, Knoxville, TN. Direct inquiries to Dr. M. P. Penfield.
Several investigators have examined the effects of tastants and foods on reducing burn after capsaicin is ingested. Stevens and Lawless (1986) determined that sucrose and citric acid produced a marked decline in intensity of burn; water and sodium chloride depressed burn somewhat, but quinine had little effect. Nasrawi and Pangborn (1990) examined the effects of sucrose, fat level and temperature on mouth-burn, using milk with two levels of fat as well as tastant solutions and ethanol. Sucrose was found to be more effective in reducing burn. They indicated that whole milk appeared to have depressed burn more than did skim milk and that the fat may have been responsible for the reduced perception of heat. Hutchinson et al. (1990) examined rice, butter, pineapple juice, and water as vehicles to reduce burn after ingestion of Tabasco sauce. Butter with a high-fat content was expected to be most effective in reducing intensity of burn because of the affinity of capsaicin for lipids. While the foods were held in the mouth, burn was reduced by all samples; when foods were expectorated, burn intensity rebounded. None of the foods was effective in reducing intensity of burn.

Intensity of burn from capsaicin in solution has been examined in many studies but little sensory research has been reported with capsaicin incorporated into food systems. Because capsaicin is lipophilic, reduction of fat in a food may alter perception of the heat of the compound in the oral cavity. Baron (1995) examined the perceived intensity of capsaicin heat in cheese sauces and starch pastes with varied fat levels at two temperatures. Serving temperature did not affect perceived intensity and perceived heat increased as fat level decreased.

As fat-reduced, high-heat food products are developed, further study of the interactions of fat and other ingredients with capsaicin will be needed. Our objective was to examine the effects of capsaicin concentration, fat level and fat mimetic on the sensory perception of heat over time in cheese sauces.

\section{METHODS \& MATERIALS}

\section{Experimental design}

A randomized block design with repeated measures was implemented as an incomplete block. The $5 \times 3 \times 4$ factorial was comprised of five capsaicin concentrations, three fat levels and four fat mimetics producing 45 treatment combinations. In the incomplete implementation, 11 panelists received three samples per day at one session for a total of 33 observations per day. Over the 150-day data collection period, each panelist evaluated all 45 combinations, forming a complete block. Experimental design software (Evolutionary Software, Inc., 1991) was used to create the presentation design. Days were the incomplete blocks; panelists were the complete blocks. The effects of concentration of capsaicin, fat level, fat mimetic and time on perceived sensory heat were investigated. The statistical model was:

$\mathrm{y}_{\mathrm{ijklmn}}=\mu+\mathrm{D}_{\mathrm{i}}+\mathrm{P}_{\mathrm{j}}+\mathrm{D}^{*} \mathrm{P}_{\mathrm{ij}}+\mathrm{C}_{\mathrm{k}}+\mathrm{fatL}_{\mathrm{l}}+\mathrm{C}^{*} \mathrm{fatL}_{\mathrm{kl}}+$ fatR(fatL) $)_{l m}+C *$ fatR(fatL) $)_{\mathrm{klm}}+\mathrm{D}^{*} \mathrm{P} * \mathrm{C} *$ fatR(fatL) $)_{\mathrm{ijklm}}+\mathrm{T}_{\mathrm{n}}+$ $\mathrm{T} * \mathrm{C}_{\mathrm{kn}}+\mathrm{T} * \mathrm{fatL}_{\mathrm{ln}}+\mathrm{T} *$ fatR(fatL) $)_{1 \mathrm{mn}}+\mathrm{T} * \mathrm{C}^{*} \mathrm{fat}_{\mathrm{kln}}+$ $\mathrm{T} * \mathrm{C} *$ fatR(fatL) $)_{\mathrm{klmn}}+\mathrm{e}_{\mathrm{ijklmn}}$

where $\mathrm{D}$ is day, $\mathrm{P}$ is panelist, $\mathrm{C}$ is capsaicin level, fatL is fat level, fat $\mathrm{R}$ is fat replacer and $\mathrm{T}$ is time of measurement. 


\section{Materials}

Cheese sauces were formulated with three levels of fat-full (FF), reduced (RF) and low (LF) (Table 1). Full-fat sauces were designed to approximate the fat content of commercial cheese sauces and dips$21 \mathrm{~g} / 100 \mathrm{~g}$ serving (Marsh, 1980). Reduced- and low-fat sauces were designed to meet approximate legal definitions of the terms; reducedfat sauces have at least $25 \%$ less fat than the full-fat product and lowfat sauces have no more than $3 \mathrm{~g} /$ serving (FDA, 1995).

Reductions in fat were achieved by replacing shortening in part or in full with a fat mimetic. The four commercial fat mimetics used included a microparticulated protein (Simplesse ${ }^{\circledR}$, Nutrasweet Kelco, Chicago, IL), a modified waxy maize starch (N-Lite $\mathrm{L}^{\circledR}$, National Starch, Bridgewater, NJ), an oat/rice-derived product (Dairytrim ${ }^{\circledR}$, Rhone-Poulenc, Cranberry, NJ) and a modified potato starch (Paselli Excel $^{\circledR}$, Avebe, Princeton, NJ). Five concentrations of capsaicin $(0$, $0.4,0.8,1.2$ and $1.6 \mathrm{ppm}$ ) were chosen to contribute heat to the cheese sauces. These concentrations increased in equal increments and provided two levels of heat intensity defined by ASTM (Method E 1083$88 \S 3,1991)$ —slight $(0.4 \mathrm{ppm})$ and moderate $(0.8 \mathrm{ppm})$ —as well as concentrations just below (1.2 ppm) and above (1.6 ppm) the level described as approaching strong $(1.3 \mathrm{ppm})$ in water samples.

Stock solutions were prepared following ASTM method E 1083$88 \S 10.1 .1-10.1 .3$ (ASTM, 1991), using 0.60g capsaicin (8-methyl$\mathrm{N}$-vanillyl-6-nonenamide, 98.0\%, Sigma Chemical Co., St. Louis, MO) and 20.0g Polysorbate-80 (Vanden Berg Foods Co., Lisle, IL). Cheese sauce powders were prepared by combining all dry ingredients in a mixer (Kitchen-Aid ${ }^{\circledR}$, Model k45ss, St. Joseph, MI) and blending at speed 2 for $2 \mathrm{~min}$. The prepared dry mix was blended in a $600-\mathrm{mL}$ beaker with lactic acid, corn syrup, water and stock solution and heated on a stirring hot plate (Barnstead/ Thermolyne, Dubuque, IA) at heat setting 6 and stirring setting $7-8$ for $12-15$ min until the mixture thickened. Levels of stock solution and water were designed to provide specified capsaicin concentrations in the sauces. After cooling, $10 \mathrm{~g}$ of sample were transferred to coded 60 -mL glasses, covered and refrigerated until needed for sensory testing.

\section{Sensory panel}

Methods outlined in ASTM Method E 1083-88 § 9.1-9.5 (1991) were used to train and select panelists from among 14 volunteer staff members and students of The University of Tennessee, Knoxville. On day 1 of training, the panelists were instructed in the use of a line scale anchored with the terms none and strong for recording sensory perception of heat. Threshold, slight and moderate levels were also indicated on the line scale. The panel received a reference sample of 0.4 ppm capsaicin and a set of water samples ranging in intensity from 0.0 to $1.3 \mathrm{ppm}$ capsaicin to evaluate. Panelists were instructed to concentrate carefully on the perception of heat and to memorize the heat levels of each sample as they experienced them. Correct ratings and definitions were given to the panel after completion of the evaluation. Terms were defined in reference to the appropriate point on the line scale. On days 2-4, panelists were given a control and two experimental (unknown) samples to evaluate. Sample identities and individual scores were discussed with each panelist after evaluation. After day 4, 13 panelists were asked to continue with the study. Over the next 5 days, panelists were introduced to the cheese sauce carriers and instructed in time-intensity techniques and computerized data entry.

\section{Time-intensity procedures}

Panelists cleansed their palates with room temperature spring water and unsalted top soda crackers before sampling; they then placed the entire reference sample ( $0.4 \mathrm{ppm}$ CAP in spring water) into the mouth and held it for $5 \mathrm{sec}$ before swallowing. Thirty seconds after swallowing, they mentally rated the intensity as being "slight." They cleansed with cracker and spring water. The entire first experimental sample was spooned into the mouth, held for $5 \mathrm{sec}$, intensity evaluated and sample swallowed slowly. Intensity was indicated at 15 -sec intervals for $180 \mathrm{sec}$. The mouth was cleansed and the procedure repeated with samples 2 and 3 .
Table 1-Dry cheese powder formulas

\begin{tabular}{lccc}
\hline & \multicolumn{3}{c}{ Fat level $^{\mathrm{a}}$} \\
\cline { 2 - 4 } Ingredient & Full & Reduced & Low \\
\hline & ---- & $--0 \%--------$ \\
Modified food starch $^{\mathrm{b}}$ & 9.8 & 17.5 & 26.2 \\
Cheese powder, full fat $^{\mathrm{c}}$ & 24.9 & 24.9 & 24.9 \\
Shortening powder $^{\mathrm{d}}$ & 29.4 & 15.5 & 0 \\
Sweet whey $^{\mathrm{e}}$ & 12.7 & 14.8 & 15.6 \\
Cheddar powder, low-fat $^{\mathrm{t}}$ & 12 & 12 & 12 \\
Fat mimetic $^{\mathrm{g}}$ & 0 & 3.3 & 6.6 \\
NFDM $^{\mathrm{h}}$ & 6.3 & 6.1 & 6.4 \\
Corn syrup $^{\mathrm{i}}$ & 0 & 1 & 3.4 \\
Salt $^{\mathrm{i}}$ & 2 & 2 & 2 \\
Blue cheese powder $^{\mathrm{j}}$ & 2.5 & 2.5 & 2.5 \\
Lactic acid $^{\mathrm{k}}$ & 0.4 & 0.4 & 0.4 \\
Total & 100 & 100 & 100 \\
& & &
\end{tabular}

aFat levels approximate content of commercial cheese sauces (full fat); $25 \%$ less than full fat (reduced fat) and no more than $3 \mathrm{~g}$ per serving (low fat) (FDA, 1995)

bFirmtex ${ }^{\circledR}$, National Starch and Chemical Company,.. Bridgewater, NJ.

cChez-tone 153 Kosher, Kerry Ingredients, Beloit, WI.

dBeatreme ${ }^{\circledR} 2784$, Kerry Ingredients, Beloit, WI.

extra-grade dry sweet whey, Land O'Lakes, Inc., Minneapolis, MN

fLowfat cheddar seasoning, Mid-America Farms, Springfield, MO.

gFat substitutes vary by treatment.

hArmour ${ }^{\circledR}$ Food Ingredients Company, Springfield, KY

iKroger, Cincinnati, OH.

jCheese-treme ${ }^{\circledR} 1923 B$, Kerry Ingredients, Beloit, WI.

kADM Arkady, Decatur, IL.

\section{Computerized data collection}

A computer sensory program developed at the Agricultural Experiment Station, University of Georgia, Griffin (Resurreccion and Chern, 1993) was used to record panelist responses. The program provided a line scaled to 150 points. For purposes of evaluating heat, the line was augmented with marks at values for the heat levels for which the panelists were trained - none (0), threshold (25), slight (50), moderate (100) and strong (150). At the end of each training session, the data were checked for evidence that each panelist perceived heat in the samples. At the end of the training period, data were evaluated for consistency in heat perception as evidenced by normal appearance of time-intensity curves.

Panelists evaluated heat in cheese sauces once a day, 3 days a week for $5 \mathrm{wk}$. After completion of sensory data collection, each panelist's data were examined for consistency of heat perception over time across the complete design. Perceptions of two panelists were found to be erratic. One exhibited evidence of desensitization to capsaicin as heat was seldom perceived in any sample. The second developed an aversion to the cheese sauces in the latter days of the study and failed to consume an adequate amount of sample to accurately judge perception of heat. Evaluations of these two panelists were deleted from the analysis.

\section{Statistical analysis}

If data lacked either equal variance or normality (checked with proc means and univariate, SAS Institute, Inc., 1989), it was transformed to meet analysis assumptions (Cochran and Cox, 1980). In order to analyze the components of a time-intensity curve, a SAS program was used to calculate the variables of interest - rate of release, maximum intensity, time to maximum intensity, perceived heat at $180 \mathrm{sec}$ and area under the time-intensity curve as well as heat intensity over time. Because the complete design and implementation were blocked on different factors, analysis of variance was performed with a mixed models procedure, PROC MIXED (SAS Institute, Inc., 1996); leastsquares means (LS means) were generated for each and the means separated using the mixed models PDIFF function. PROC GPLOT (SAS Institute, Inc. 1990) was used to graph relationships between design factors and predicted perceived heat.

\section{RESULTS \& DISCUSSION}

PERCEPTION OF HEAT INTENSITY RESULTING FROM ORAL INGESTION of capsicums is temporal-over the passage of time, perceived heat may intensify and/or decrease in relation to the heat component of the pepper and the chemical composition of the food mixture in which it is 
found. Rate of release (RATE), perceived heat at $180 \mathrm{sec}$, time to maximum intensity (TMAX), heat intensity over time, maximum intensity (IMAX), and total intensity as area under the time/intensity curve were assessed (Lee and Pangborn, 1986).

No differences attributable to fat mimetic were found in the intensity parameters. Differences which occurred in RATE and perceived heat at $180 \mathrm{sec}$ were attributable to the concentration of capsaicin; both increased as CAP increased $(\mathrm{p}<0.05)$. The increases reflected the established linear relationship between capsaicin concentration and sensory heat perception (Krajewska and Powers, 1988). TMAX was influenced by fat level; panelists recorded maximum heat a few seconds earlier for reduced-fat sauces than for LF sauces $(\mathrm{p}<0.02)$. TMAX of full-fat sauces $(38.7 \pm 7.6)$ did not differ from that required for reduced- $(29.6 \pm 6.2)$ and low-fat $(37.6 \pm 6.2)$ sauces $(\mathrm{p}>0.05)$.

\section{Heat intensity over time}

Heat intensity over the $180 \mathrm{sec}$ was affected by capsaicin (CAP) concentration, fat level, time and interactions of CAP $\times$ time and CAP $X$ fat level. Time intensity curves indicated differences across time among levels of CAP(Fig. 1). At $5 \mathrm{sec}$, sauces containing 0.8, 1.2 and $1.6 \mathrm{ppm}$ CAP were perceived as more pungent than those with 0.0 and $0.4 \mathrm{ppm}$ CAP $(\mathrm{p}<0.05)$. Sauces with 1.2 and $1.6 \mathrm{ppm}$ did not differ $(\mathrm{p}>0.05)$, but both had LSmean intensity ratings higher than sauces containing $0.8 \mathrm{ppm}$ CAP $(\mathrm{p}<0.05)$. Panelists perceived heat intensity at highest levels earlier and indicated that the intensity decayed more rapidly $(\mathrm{p}<0.05)$ in sauces containing 0.0 or 0.4 ppm CAP than in other sauces. At like times, levels of intensity perceived by panelists in cheese sauces with 0.8 ppm CAP differed from intensities of other sauces. Differences were not found between 1.2 and 1.6 ppm CAPcontaining sauces until panelists passed the $45-\mathrm{sec}$ rating.

Differences in heat intensity over time attributable to fat were related to capsaicin concentration (Fig. 2). While no differences in LSmeans occurred in perceived heat among fat levels at 0.0 and $0.4 \mathrm{ppm}$ CAP. RF and LF sauces with $0.8 \mathrm{ppm}$ were perceived as higher in heat

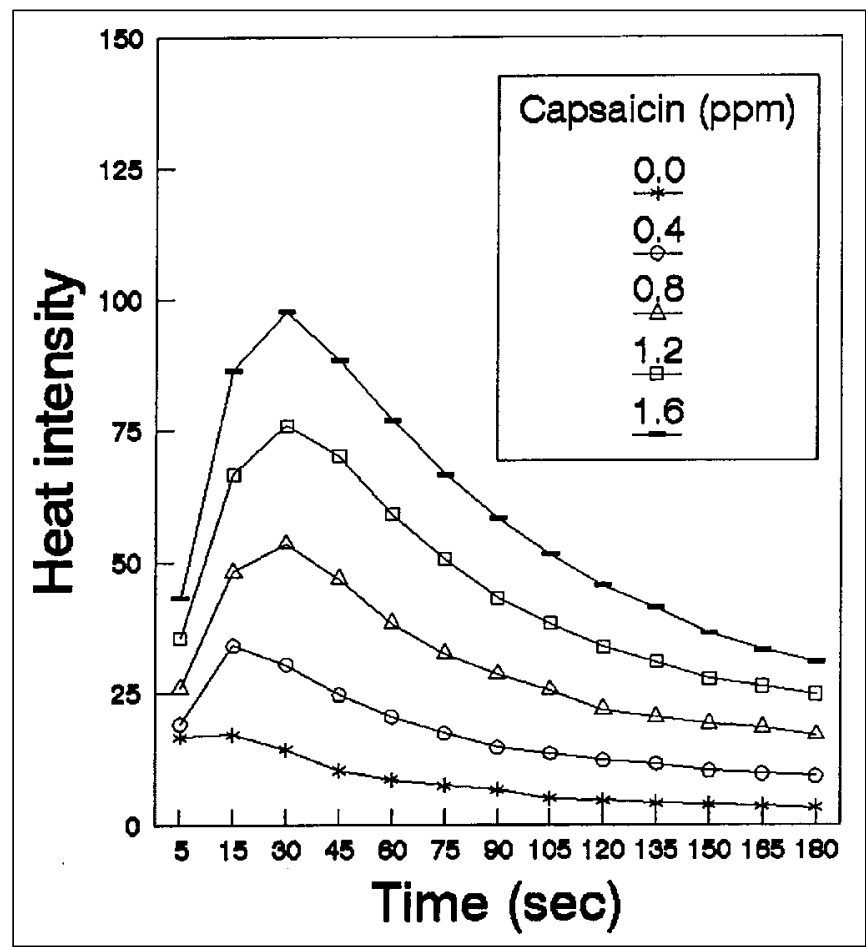

Fig. 1-LS mean estimates of perceived heat intensity as a function of time $x$ capsaicin concentration. Cheese sauces formulated with five levels of capsaicin across three fat levels and four fat mimetics were evaluated by 11 panelists at 15-sec intervals over a period of 180 sec on a rating scale anchored by the terms none $=0$ and strong $=150$.
Table $2-R^{2}$ values for regression equations (illustrated in Fig. 3-5)

\begin{tabular}{cclccc}
\hline & & & \multicolumn{3}{c}{ Fat level $^{\mathrm{a}}$} \\
\cline { 4 - 6 } Fig. & Attribute & & Low & Reduced $^{\text {Full }}$ \\
\hline 3 & \multirow{2}{*}{ Heat } & Linear & 0.336 & 0.299 & 0.295 \\
& & Quadratic & 0.336 & 0.299 & 0.315 \\
4 & \multirow{2}{*}{ Maximum heat } & Linear & 0.650 & 0.653 & 0.589 \\
& & Quadratic & 0.651 & 0.589 & 0.625 \\
5 & Total intensity & Linear & 0.525 & 0.486 & 0.508 \\
& & Quadratic & 0.526 & 0.486 & 0.541 \\
\hline
\end{tabular}

aFat levels approximate content of commercial cheese sauces (full fat); $25 \%$ less than full fat (reduced fat) and no more than $3 g$ per serving (low fat) (FDA, 1995).

intensity than FF 0.8 CAP sauce $(\mathrm{p}<0.001)$. The FF sauces at 0.8 ppm CAP were perceived at the same intensity level as RF and FF sauces with $0.4 \mathrm{ppm}$ CAP $(\mathrm{p}>0.05)$. Heat in LF sauces at $1.2 \mathrm{ppm}$ CAP was perceived at a higher level than in FF sauces $(\mathrm{p}<0.0001)$. Perceived heat in FF sauces at 1.6 ppm CAP equalled that in both RF and LF sauces $(p>0.05)$. As an additional visual representation of the interaction of fat level and CAP concentration, predicted relationships based on perceived heat intensity were modeled with quadratic and linear relationships included; true linear lines were plotted as reference points (Fig. 3). $\mathrm{R}^{2}$ values for the regression equation are reported (Table 2). With quadratic relationships included in the model, RF and LF sauces increased almost linearly in perceived heat as CAP increased. However, FF sauces exhibited a curvilinear depression between 0.4 and 1.2 ppm CAP, supporting the hypothesis that the higher-fat level depressed the perception of heat intensity. This differed from the findings of Baron and Penfield (1996) that there was no effect of fat level on heat perception over time in cheese carriers.

\section{Maximum heat}

Maximum heat (IMAX) is the highest intensity perceived by panelists over the 180-sec evaluation period. As expected, IMAX increased $(\mathrm{p}<0.001)$ as CAP level increased. Because capsaicin is a fatsoluble compound, we expected that fat may influence the perception of maximum heat. Least-squares analysis of IMAX ratings supported

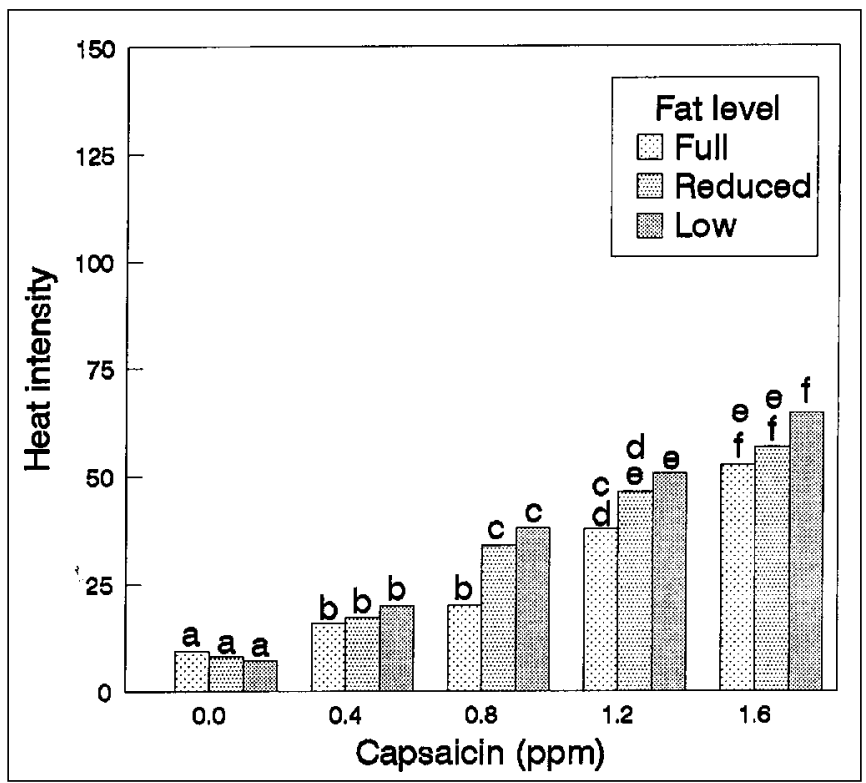

Fig. 2-LSmean estimates of perceived heat intensity across time as a function of fat level and capsaicin concentration. Sauces were formulated with three levels of fat and five levels of capsaicin. Reduced-fat and low-fat means are across four fat mimetic. Eleven panelists evaluated sauces on a rating scale anchored with the terms none $=0$ and strong=150. Bars with unlike letters differ at $p<0.05$. 
that expectation. LSmean ratings of perceived heat increased as fat level decreased, but the pattern was related to CAP concentration (Table 3). Larger standard errors for FF LS means were attributable to the lower number of samples that influenced detection of differences. With no CAP in the sauces, panelists rated maximum heat at a level below "slight" $(25)$ on the scale. Panelists seemed to avoid the 0 on the scale for samples with no CAP; this likely is related to the error of central tendency (Stone and Sidel, 1993). No difference in IMAX across fat levels was indicated by LSmeans at 0.0 or 0.4 ppm CAP $(p>0.05)$. At 0.8 ppm CAP, LS mean estimates of perceived maximum heat differed among the fat levels; FF sauces had an LS mean maximum heat lower than either RF or LF sauces $(\mathrm{p}<0.05)$. At a CAP level of $1.2 \mathrm{ppm}$, FF sauces were perceived as having less maximum heat than LF $(\mathrm{p}<0.0001)$, but did not differ from RF ( $p>0.05)$. With a concentration of $1.6 \mathrm{ppm}$ CAP, FF sauce LS means differed from neither RF nor $\operatorname{LF}(\mathrm{p}>0.05)$. Between RF and LF sauces at equal CAP concentrations, differences in IMAX occurred only at $1.6 \mathrm{ppm}$ CAP $(\mathrm{p}<0.0001)$. As CAP concentration increased above the $0.8 \mathrm{ppm}$ level, LS mean estimates indicated that panelists perceived IMAX in full-fat sauces at an intensity equal to IMAX in RF sauces. At 1.6 ppm, IMAX in FF sauces did not differ from either RF or LF sauces. In RF and LF sauces, moderate CAP concentrations $(0.8 \mathrm{ppm})$ were perceived at a maximum level of heat equal to that assigned by panelists to higher concentrations (1.2 ppm) in FF sauces.

Including quadratics in the statistical model to predict the relationship between fat and CAP clarified the influence of fat in the interaction (Fig. 4, Table 2). In RF and LF sauces, a slight trend toward a positive curvilinear relationship between fat level and capsaicin concentration was predicted as CAP increased to 0.8 and 1.2 ppm CAP. In FF sauces, the opposite trend was seen; the effect of CAP $\times$ fat level at CAP levels between 0.4 and $1.2 \mathrm{ppm}$ was shown by the negative response of the quadratic component in the formula. At the full-fat level, lower levels of maximum heat were predicted at $0.8 \mathrm{ppm}$ CAP than at reduced- and low-fat levels. At 1.2 ppm CAP, maximum heat was lower in FF sauces than in low-fat. The interaction of fat with

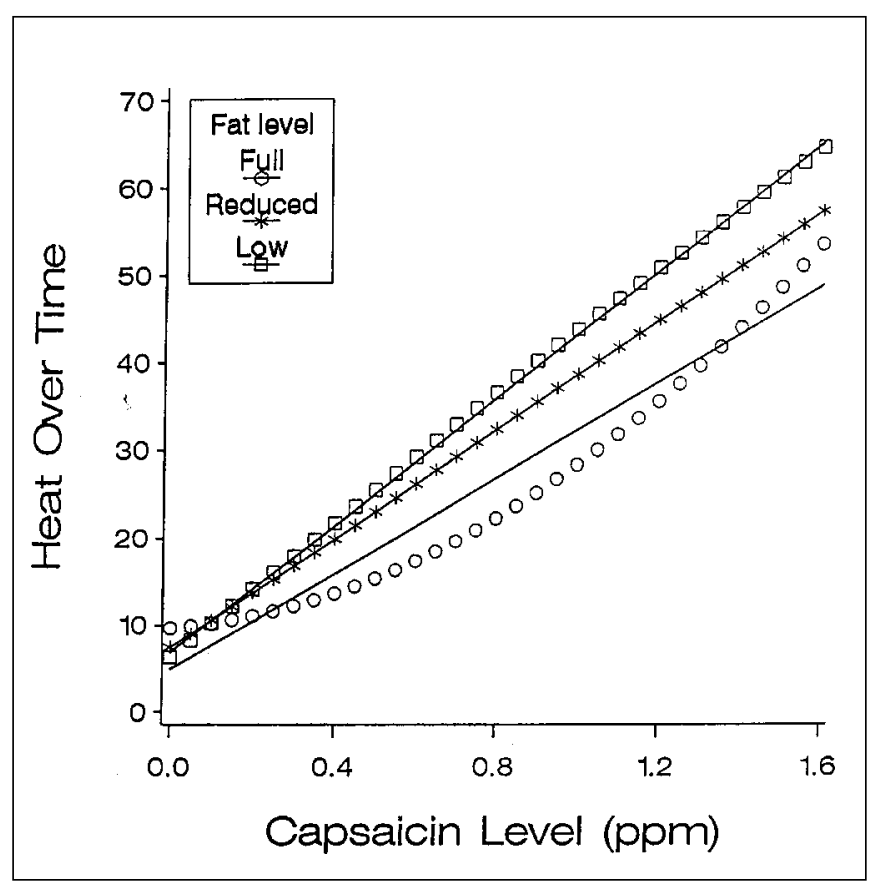

Fig. 3-Predicted perceived heat as a function of fat level $\times$ capsaicin. The statistical model included linear and quadratic functions with a linear line drawn in for reference. Sauces formulated with three fat levels and five capsaicin concentrations were evaluated by 11 panelists on a rating scale anchored by the terms none $=0$ and strong $=150$.
Table 3-Sensory perception of maximum heat intensity in cheese sauces formulated with three fat levels and five capsaicin levels ${ }^{a}$

\begin{tabular}{ccccccc}
\hline & \multicolumn{6}{c}{ Fat level $^{\mathbf{b}}$} \\
\cline { 2 - 7 } $\begin{array}{c}\text { Capsaicin } \\
\text { (ppm) }\end{array}$ & \multicolumn{7}{c}{ Full $^{\mathbf{c}}$} & \multicolumn{2}{c}{ Reduced $^{\mathbf{d}}$} & \multicolumn{2}{c}{ Low $^{\text {d }}$} \\
\hline 0 & $23.3 \mathrm{ab}$ & \pm 7.1 & $20.1 \mathrm{a}$ & \pm 4.5 & $19.5 \mathrm{a}$ & \pm 4.5 \\
0.4 & $37.6 \mathrm{bc}$ & \pm 7.1 & $38.2 \mathrm{c}$ & \pm 4.5 & $40.1 \mathrm{c}$ & \pm 4.5 \\
0.8 & $41.3 \mathrm{c}$ & \pm 7.1 & $66.7 \mathrm{~d}$ & \pm 4.5 & $71.1 \mathrm{~d}$ & \pm 4.5 \\
1.2 & $74.7 \mathrm{de}$ & \pm 7.1 & $88.0 \mathrm{ef}$ & \pm 4.5 & $92.7 \mathrm{fg}$ & \pm 4.5 \\
1.6 & $101.7 \mathrm{ghi}$ & \pm 7.1 & $102.3 \mathrm{~h}$ & \pm 4.5 & $112.1 \mathrm{i}$ & \pm 4.5 \\
\hline
\end{tabular}

aLSmean \pm std err of the maximum values of perceived heat; none $=0$, strong $=150$; values followed by unlike letters differ at $p<0.05$.

bFat levels approximate content of commercial cheese sauces (full fat); $25 \%$ less than full fat (reduced fat) and no more than $3 g$ per serving (low fat) (FDA, 1995)

cValues for 11 panelists $(n=11)$.

dValues for 11 panelists across four fat mimetic $(n=44)$.

capsaicin was predicted to decrease perception of heat at moderate concentrations of capsaicin.

\section{Total intensity}

The area under a time-intensity curve (AREA) represents total perceived intensity. In our results, AREA was the total heat perceived over the 180 -sec measurement period. Differences in total intensity were affected by fat level $(\mathrm{p}<0.0001)$, capsaicin concentration $(p<0.0001)$ and an interaction between fat and CAP $(p<0.05)$. Total perceived heat differed as expected across CAP concentrations. Increasing levels of CAP increased total intensity $(\mathrm{p}<0.0001)$ as higher concentrations of CAP would contact more receptors within the oral cavity. Inclusion of capsaicin in a fat-containing food may result in a failure of the capsaicin molecule to adhere completely to oral receptors as fat may shield such receptors from CAP. Analysis of the data supports this hypothesis since total intensity increased as fat decreased. When fat level and CAP concentration were examined in concert, these differences were evident (Table 4). In FF sauces, AREA did not differ $(\mathrm{p}>0.05)$ among the three lower capsaicin concentrations -0.0 , 0.4 and $0.8 \mathrm{ppm}(\mathrm{p}>0.05)$. A sharp increase $(\mathrm{p}<0.05)$ in total intensi-

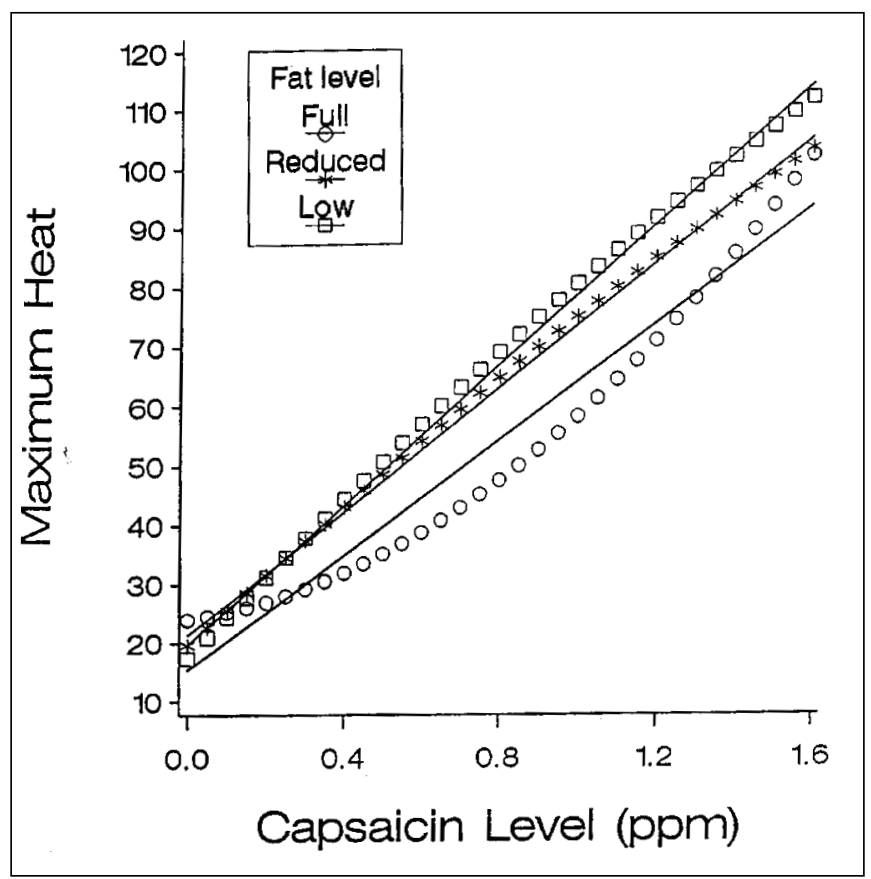

Fig. 4-Predicted perceived maximum heat as a function of fat level $\times$ capsaicin. Model included linear and quadratic functions with a linear line provided as a reference. Sauces formulated with three fat levels and five capsaicin concentrations were evaluated by 11 panelists on a rating scale anchored by the terms none $=0$ and strong $=150$. 
Table 4-Sensory perception of total heat intensity in cheese sauces prepared with three fat levels and five capsaicin levels ${ }^{\mathrm{b}}$

\begin{tabular}{clcccrc}
\hline & \multicolumn{5}{c}{ Fat level $^{\mathbf{c}}$} \\
\cline { 2 - 7 } $\begin{array}{c}\text { Capsaicin } \\
\text { (ppm) }\end{array}$ & \multicolumn{1}{c}{ Full $^{\mathbf{d}}$} & \multicolumn{2}{c}{ Reduced $^{\mathbf{e}}$} & \multicolumn{1}{c}{ Low $^{\mathbf{e}}$} \\
\hline 0.0 & $1617.1 \mathrm{ab}$ & \pm 1063.5 & $1400.6 \mathrm{a}$ & \pm 859.9 & $1206.6 \mathrm{a}$ & \pm 859.1 \\
0.4 & $2759.1 \mathrm{abc}$ & \pm 1063.1 & $3040.3 \mathrm{bc}$ & \pm 859.2 & $3574.6 \mathrm{c}$ & \pm 859.0 \\
0.8 & $3564.7 \mathrm{bc}$ & \pm 1064.3 & $6116.3 \mathrm{~d}$ & \pm 859.0 & $6855.0 \mathrm{~d}$ & \pm 858.4 \\
1.2 & $6757.1 \mathrm{~d}$ & \pm 1063.2 & $8394.8 \mathrm{e}$ & \pm 858.5 & $9222.7 \mathrm{e}$ & \pm 858.2 \\
1.6 & $9519.5 \mathrm{ef}$ & \pm 1063.1 & $10349.2 \mathrm{f}$ & \pm 859.0 & $11845.2 \mathrm{~g}$ & \pm 859.5 \\
\hline
\end{tabular}

aTotal heat intensity as area under the time-intensity curve. Measurements taken at $15 \mathrm{sec}$ intervals over $180 \mathrm{sec}$ on a scale of none $=0$, strong $=150$.

Values are LS means \pm std errors; values with unlike letters differ at $p<0.05$

'Fat levels approximate content of commercial cheese sauces (full fat); $25 \%$ less than full fat (reduced fat) and no more than $3 \mathrm{~g}$ per serving (low fat) (FDA, 1995)

dValues for 11 panelists $(n=11)$

eValues for 11 panelists across 4 fat mimetic $(n=44)$

ty occurred at $1.2 \mathrm{ppm}$ CAP and again at $1.6 \mathrm{ppm}$ CAP. This effect of increasing AREA with increasing CAP differed in RF and LF sauces; AREA increased with each increase in capsaicin concentration $(\mathrm{p}<0.05)$. Among fat levels across CAP concentrations, total intensity did not differ at 0.0 or 0.4 ppm CAP. However, a difference occurred between FF and the two sauces with decreased fat content at 0.8 and $1.2 \mathrm{ppm}$ CAP $(\mathrm{p}<0.0001)$. At $1.6 \mathrm{ppm}$ CAP, total intensity of FF sauces did not differ from RF ( $p>0.05)$, but was less than that of LF sauces $(p<0.05)$. Reduced fat sauces differed from LF sauces only at $1.6 \mathrm{ppm}$ CAP $(\mathrm{p}<0.01)$. A distinctive pattern of increased perceived heat developed as fat level decreased and CAP concentration increased. The role of fat in the effect of the interaction between fat level and CAP on total intensity of perceived heat in cheese sauces could be predicted graphically using regression analysis (Fig. 5, Table 2). The difference appears to be possibly attributable to the increasing capsaicin concentrations. The presence of the quadratic in the statistical model however, reveals a similarity of total intensity to the graphical representations of the predicted fat $X$ CAP interactions in heat perceived over time and maximum heat.

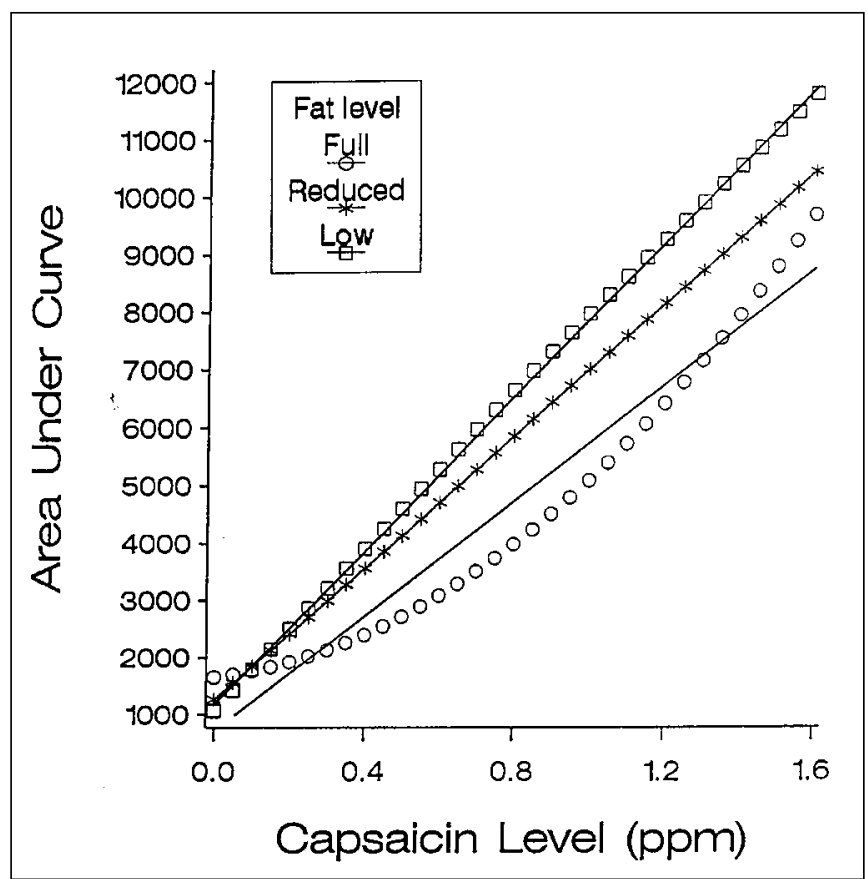

Fig. 5-Predicted area under the time intensity curve as a function of fat level $\times$ capsaicin. Statistical model included linear and quadratic functions with a linear reference line. Sauces formulated with three fat levels and five capsaicin concentrations were evaluated by 11 panelists on a rating scale anchored by the terms none $=0$ and strong $=150$.
Between CAP levels 0.4 and 1.2, a slight curvilinear depression in total intensity occurred in the FF sauces. This negative curve did not appear in LF and RF sauces which appeared to increase linearly in total intensity of perceived heat. This indicated that full-fat content decreased perception of heat intensity at lower levels of capsaicin. The combination of fat and capsaicin at 0.4 and $0.8 \mathrm{ppm}$ decreased the ability of the capsaicin molecule to contact trigeminal receptors, reducing the total intensity of perceived heat by panelists. Higher concentrations of capsaicin-1.2 and $1.6 \mathrm{ppm}$ - at the full-fat level could still stimulate heat perception receptors.

In our results, heat intensity over time, maximum heat and total intensity perceived in cheese sauces increased as capsaicin concentration increased, reflecting results of previous studies (Lawless, 1984; Baron, 1995; Baron and Penfield, 1996). Sauces with the high-fat level exhibited lower heat intensities over time at concentrations of capsaicin between 0.4 and $1.2 \mathrm{ppm}$ and maximum heat was similarly affected. Perception of maximum heat in reduced- and low-fat sauces at $0.8 \mathrm{ppm}$ capsaicin and in low-fat sauces at $1.2 \mathrm{ppm}$ capsaicin was greater than in full-fat sauces. No differences in perceived heat were found among the types of fat mimetic. This suggests that manufacturers of capsaicin-containing reduced-and low-fat sauces may select starch- or protein-based mimetics based upon needed functional properties. Carbohydrate- and protein-based mimetics did not affect heat in reduced- and low-fat cheese sauces, but lipid-based replacers have a greater potential to do so and their effects on perception of heat should be studied further.

\section{REFERENCES}

ASTM. 1991. Standard Test Method for Sensory Evaluation of Red Pepper Heat, Method 15.07:E 1083-88, p. 45. 1991 Annual Book Of ASTM Standards. American Society for Testing and Materials, Philadelphia, PA.

Baron, R.F. 1995. Carrier type, fat content, capsaicin concentration and sample temperature: Effects on perceived pungency. PhD Dissertation, The Univ. of Tennessee, Knoxville.

Baron, R.F. and Penfield, M.P. 1996. Capsaicin heat intensity-Concentration, carrier, fat level, and serving temperature effects. J. Sensory Stud. 11: 295-315.

Bosland, P.W. 1992. Chillies; a diverse crop. Hort. Technol. 2(1): 6-10.

Cochran, W.G. and Cox, G.M. 1957. Experimental Designs, 2nd ed. John Wiley and Sons, Inc., New York.

Evolutionary Software, Inc. 1991. E4 ${ }^{\circledR}$ Users Guide, Ver. 91.1, Evolutionary Software, Inc., Knoxville, TN.

FDA. 1995. \$101.62. Nutrient content claims for fat, fatty acid, and cholesterol content of foods. Code of Federal Regulations. 21 Parts 100 to 169. U.S. Govt. Printing Office, Washington, DC

Glicksman, M. 1991. Hydrocolloids and the search for the "Oily Grail." Food Technol. 45(10): $94-103$

Hutchinson, S.E., Trantow, L.A., and Vickers, Z.M. 1990. The effectiveness of common foods for reduction of capsaicin burn. J. Sensory Stud. 4: 157-164.

Krajewska, A.M. and Powers, J.J. 1988. Sensory properties of naturally occurring capsaicinoids. J. Food Sci. 53: 902-905.

Lawless, H. 1984. Oral chemical irritation: psychophysical properties. Chem. Senses 9: $143-155$.

Lee, W.E. and Pangborn, R.M. 1986. Time-intensity: the temporal aspects of sensory perception. Food Technol. 40 (11): 71-78

Marsh, A.C. 1980. Agricultural Handbook 8-6: Composition of Foods, Soups, Sauces, and Gravies. 184, 204. USDA, Washington, DC.

Nasrawi, C.W. and Pangborn, R.M. 1989. The influence of tastants on oral irritation by capsaicin. J. Sensory Stud. 3: 287-294.

Nasrawi, C.W. and Pangborn, R.M. 1990. Temporal effectiveness of mouth-rinsing on capsaicin mouth-burn. Phys. Behav, 47: 617-623.

Prescott, J., Allen, S., and Stephens, L. 1984. Interactions between oral chemical irritation, taste and temperature. Chem. Senses $18: 389-404$.

Plug, H. and Haring, P. 1993. The role of ingredient-flavor interactions in the development of fat-free foods. Trends Food Sci. Technol. 4:150-152.

Resurreccion, A.V.A. and Chern, J.S. 1993. Sensory Evaluation Computer Program. Agricultural Experiment Station, Univ. of Georgia, Griffin.

Rosin, S. and Tuorila, H. 1992. Flavor potency of garlic, pepper and their combination in different dispersion media. Lebensm.-Wiss. u.-Technol. 25: 139-42.

SAS Institute, Inc. 1989. SAS User's guide: Statistics, Ver. 6 Ed. SAS Institute Inc., Cary, NC.

SAS Institute, Inc. 1990. SAS/Graph Software: Reference, Ver 6 1st ed. SAS Institute, Inc., Cary, NC.

SAS Institute, Inc. 1996. Sas/Stat ${ }^{\circledR}$ Software: Changes and Enhancements through Release 6.11. SAS Institute, Inc., Cary, NC.

Shamil, S., Wyeth, L.J., and Kilcast, D. 1992. Flavour release and perception in reducedfat foods. Food Qual. Pref. $3: 51-60$.

Stevens, D.A. and Lawless, H.T. 1986. Putting out the fire: Effects of tastants on oral chemical irritation. Percep. Psych. 39(5): 346-350.

Stone, H. and Sidel, J.L. 1993. Sensory Evaluation Practices, 2nd ed. Academic Press, Inc., San Diego, CA.

USDHHS. 1988. The Surgeon-General's Report on Nutrition \& Health: DHSS (PHS) Publication No. 88-50215, U.S. Department of Health and Human Services, U.S. Government Printing Office, Washington, DC

Ms received 1/10/98; revised 7/7/98; accepted 7/19/98.

Funding for this project was provided by the Tennessee Agricultural Experiment Station (Project TENN065). Appreciation is expressed to Christina Perry and Margaret Keller who assisted with preparation of the samples and to the panelists who generously devoted their time. 